\title{
Evaluation of urinary N-acetyl-beta- D-glucosaminidase as a marker of early renal damage in patients with type 2 diabetes mellitus
}

\author{
Avaliação da N-acetil-beta-D-glucosaminidase urinária como marcador \\ de dano renal precoce em pacientes com diabetes melito tipo 2
}

Beatriz R. Bouvet' ${ }^{1}$ Cecilia V. Paparella', Sandra M. M. Arriaga' Adriana L. Monje' ${ }^{2}$, Ana M. Amarilla' ${ }^{1}$ Adriana M. Almará ${ }^{1}$

${ }^{1}$ Clinical Biochemistry Department, Facultad de Ciencias Bioquímicas y Farmacéuticas, Universidad Nacional de Rosario, Rosario, Santa Fe, Argentina

${ }^{2}$ Nephrology Service, Facultad de Ciencias Médicas. Universidad Nacional de Rosario, Rosario, Santa Fe, Argentina
Correspondence to: Adriana M. Almará Facultad de Ciencias Bioquímicas y Farmacéuticas Suipacha, 531

S2002LRK - Rosario, Santa Fe Argentina

aalmara@fbioyf.unr.edu.ar

Received on Sept/25/2013 Accepted on Oct/13/2014

DOI: 10.1590/0004-2730000003010

\begin{abstract}
Objective: To evaluate the clinical usefulness of urinary $\mathrm{N}$-acetyl-beta-D-glucosaminidase (NAG) excretion for the detection of early tubular damage in type 2 diabetes mellitus (T2DM). Subjects and methods: Thirty six patients with T2DM were divided into two groups based on urinary albumin to creatinine ratio (ACR): normoalbuminuria ( $A C R<30 \mathrm{mg} / \mathrm{g} ; \mathrm{n}=19$ ) and microalbuminuria ( $A C R=30-300 \mathrm{mg} / \mathrm{g} ; \mathrm{n}=17$ ). The following parameters were determined in both groups: urinary NAG and albumin, serum and urine creatinine, fasting plasma glucose and glycated hemoglobin $\left(\mathrm{HbA}_{1 \mathrm{c}}\right)$. Results: Urinary NAG levels [Units/g creatinine; median (range)] were significantly increased in microalbuminuria group [17.0 (5.9 - 23.3)] compared to normoalbuminuria group [4.4 (1.5 - 9.2)] $(P<0.001)$. No differences between groups were observed in fasting glucose, $\mathrm{HbA}_{1 c^{\prime}}$ serum creatinine levels and estimated glomerular filtration rates (eGFR). Urinary NAG positively correlated with ACR $(r=0.628 ; p<0.0001)$, while no significant association was observed between NAG and glycemia, $\mathrm{HbA}_{1 c^{\prime}}$ serum creatinine and eGFR. Conclusions: The increase of urinary NAG at the microalbuminuria stage of diabetic nephropathy (DN) suggests that tubular dysfunction is already present in this period. The significant positive association between urinary NAG excretion and ACR indicates the possible clinical application of urinary NAG as a complementary marker for early detection of DN in T2DM. Arq Bras Endocrinol Metab. 2014;58(8):798-801
\end{abstract}

Keywords

Diabetic nephropathy; type 2 diabetes mellitus; tubular dysfunction; N-acetyl-beta-D-glucosaminidase; microalbuminuria

\section{RESUMO}

Objetivo: Avaliar a utilidade clínica da excreção urinária da N-acetil-beta-D-glucosaminidase (NAG) para a detecção de dano tubular precoce no diabetes melito tipo 2 (DM2). Sujeitos e métodos: Foram estudados trinta e seis pacientes com DM2 que se dividiram em dois grupos com base na excreção urinária de albumina (EUA): normoalbuminúrico (EUA $<30 \mathrm{mg} / \mathrm{g}$ de creatinina; $\mathrm{n}=19$ ) e microalbuminúrico (EUA = 30-300 mg/g de creatinina; $n=17$ ). Em ambos os grupos foram determinados os seguintes parâmetros: NAG e albumina urinária, creatinina sérica e urinária, glicemia de jejum e hemoglobina glicada $\left(\mathrm{HbA}_{1 c}\right)$. Resultados: Os níveis de $\mathrm{NAG}$ urinária [unidades/g de creatinina; mediana (intervalo interquartílico)] foram significativamente maiores no grupo microalbuminúrico $[17,0(5,9-23,3)]$ em comparação com o grupo normoalbuminúrico [4,4 $(1,5-9,2)]$ $(p<0,001)$. Não se observaram diferenças significativas entre os dois grupos nos níveis de glicemia de jejum, $\mathrm{HbA}_{1 c^{\prime}}$ creatinina sérica e taxa de filtração glomerular estimada (TFGe). A NAG urinária se correlacionou positivamente com o $\operatorname{EUA}(r=0,628, p<0,0001)$, não sendo observada associação significativa da NAG com glicemia, $\mathrm{HbA}_{1 c^{\prime}}$ creatinina sérica e TFGe. Conclusões: $\mathrm{O}$ aumento da NAG urinária na fase de microalbuminúria da nefropatia diabética (ND) sugere que a disfunção tubular já está presente nesse período. A associação positiva significativa entre a excreção urinária da NAG e EUA indica a possível aplicação clínica da NAG urinária como marcador complementar para a detecção precoce da ND no DM2. Arq Bras Endocrinol Metab. 2014;58(8):798-801

\section{Descritores}

Nefropatia diabética; diabetes melito tipo 2; disfunção tubular; N-acetil-beta-D-glucosaminidase; microalbuminúria 


\section{INTRODUCTION}

$\mathrm{D}$ iabetic nephropathy (DN) is a major microvascular complication of diabetes mellitus (DM) becoming the main cause of end-stage renal disease worldwide. It is assumed that a urinary albumin excretion within the range of microalbuminuria constitutes the first clinical evidence of DN and is the most important non-invasive marker of glomerular alteration and disease progression risk. Indeed, in diabetic patients, microalbuminuria commonly precedes both clinical albuminuria and the decline of renal function (1). On the other hand, tubular injury may also be involved in the pathogenesis and progression of DN. A wide variety of causes related with the pathophysiological alterations that develop in the setting of diabetes are contributing factors. Examples are hyperglycemia, alterations in vasoactive hormones, formation of glycation advanced end products, hemodynamic changes, protein kinase $\mathrm{C}$ activation, increased oxidative stress and polyol production (2). Furthermore, persistent albuminuria secondary to glomerular lesions may be directly harmful to renal tubular cells, leading to tubular inflammation and tubulointerstitial fibrosis $(3,4)$. One widely used tubular injury marker is $\mathrm{N}$-acetyl-beta-D-glucosaminidase (NAG) whose presence in the urine invariably signifies tubular damage since, due to its high molecular weight, it is not able to filter by the glomerulus, but it is released in the tubular lumen as a consequence of proximal tubular damage (5). Studies aimed at evaluating the utilization of urinary NAG as a marker of tubular dysfunction in type $2 \mathrm{DM}$ (T2DM) have not been conclusive. While some authors demonstrated that urinary NAG is elevated in type 2 diabetic patients with normoalbuminuria compared to non-diabetic controls (6-8), as well as in type 2 diabetic patients with microalbuminuria compared to those with normoalbuminuria (810), others disagree with these findings (11).

The aim of this study was to evaluate the clinical utility of urinary NAG excretion for the detection of early tubular dysfunction, particularly referred to the possible degree of association with urinary albumin excretion in type 2 diabetic patients.

\section{SUBJECTS AND METHODS}

We studied 36 patients with T2DM of more than 5 five years of evolution who were referred from the Medical Clinic Service to the Nephrology Service of the Hospi- tal Provincial del Centenario of Rosario. The exclusion criteria were body mass index $(\mathrm{BMI}) \geq 30 \mathrm{~kg} / \mathrm{m}^{2}$, history of other endocrinopathies, hypertension (median of blood pressure $>130 / 80 \mathrm{mmHg}$ determined as triplicates, recorded in 2 different opportunities), urinary tract infection, renal lithiasis (discarded by kidney ultrasonography), proteinuria, abnormal urinary sediment (presence of hematuria, pyuria and/or casts) or renal failure [estimated glomerular filtration rate (eGFR) $<60 \mathrm{~mL} / \mathrm{min}$ per $1.73 \mathrm{~m}^{2}$ ] (12). Normoalbuminuria was defined as urinary albumin to creatinine ratio (ACR) $<30 \mathrm{mg} / \mathrm{g}$ and microalbuminuria as ACR $=30-300$ $\mathrm{mg} / \mathrm{g}(12,13)$. Diabetic patients were categorized into two groups based on their ACR: normoalbuminuria $(\mathrm{n}=19)$ and microalbuminuria $(\mathrm{n}=17)$. In the normoalbuminuria group, 5 patients were under diet therapy, 10 patients received metformin combined with sulfonylureas and 4 patients were in treatment with insulin. In the microalbuminuria group, the number of patients under diet, metformin combined with sulfonylureas or insulin were 3,8 and 6, respectively. Ethical approval was obtained from the Ethics Committee of the Faculty of Biochemical and Pharmaceutical Sciences of Rosario.

After 12 hours of overnight fasting, venous blood samples were obtained and first morning urine samples were collected from each individual. Aliquots of urine were then immediately frozen at $-80{ }^{\circ} \mathrm{C}$ until further analysis for no longer than 1 month. Urinary excretion of NAG was measured by colorimetric assay following manufacturer's instructions (Roche Diagnostics $\mathrm{GmbH}$ ) and results were expressed as Units/g creatinine (9). The tests were run in duplicates. Intra-assay variation coefficient was $<5 \%$. Urinary concentration of albumin was assessed by an immunoturbidimetric method (Roche Diagnostics GmbH) and ACR was expressed as $\mathrm{mg} / \mathrm{g}$ creatinine $(12,13)$. Microalbuminuria was established when two out of three ACR determinations were found to be within the range $30-300 \mathrm{mg} / \mathrm{g}$ in a six-month period. Creatinine concentration in urine and serum was measured by a kinetic method based on Jaffe reaction. Serum creatinine values were used to calculate an eGFR, by means of the abbreviated Modification of Diet in Renal Disease formula $(8,13)$. Glycemic control was evaluated by assessing fasting plasma glucose and glycated hemoglobin $\left(\mathrm{HbA}_{\mathrm{lc}}\right)$. Glucose was determined by an enzymatic method in a plasma sample obtained with EDTA/fluoride. $\mathrm{HbA}_{\mathrm{lc}}$ was measured by ion-exchange cromatography (Biosystem S. A.) in a whole blood sample obtained with EDTA. 
Normally distributed values were expressed as means $\pm \mathrm{SD}$ and compared using the independent-samples $t$ test, whereas non-normally distributed values were given as median (range) and compared by the MannWhitney $\mathrm{U}$ test. After non-normally distributed values were log-transformed to better approximate normal distributions, correlations were calculated by Pearson's correlation analysis. Categorical data were compared by chi-square test. $\mathrm{P}$ values of less than 0.05 were considered statistically significant.

\section{RESULTS}

Clinical characteristics of type 2 diabetic patients are summarized in table 1 . Microalbuminuria group showed higher levels of ACR (by design) and urinary NAG compared to normoalbuminuria group $(\mathrm{P}<$ $0.001)$. We found no statistically significant differences between both groups in the time of evolution of DM, nor in blood pressure, $\mathrm{BMI}$, fasting glucose, $\mathrm{HbA}_{\mathrm{lc}}$, serum creatinine levels or eGFR.

Urinary NAG levels were positively correlated with ACR levels in all diabetic patients $(\mathrm{r}=0.628 ; \mathrm{P}<0.0001)$ (Figure 1), while no correlation was found between urinary NAG and age, blood pressure, BMI, parameters of glycemic control, serum creatinine and eGFR (Table 2).

Table 1. Clinical characteristics of patients with type 2 diabetes mellitus

\begin{tabular}{lcc}
\hline & Normoalbuminuria & Microalbuminuria \\
\hline $\mathrm{n}$ & 19 & 17 \\
Age (years) & $68 \pm 8$ & $64 \pm 13$ \\
Gender (M/F) & $13 / 6$ & $8 / 9$ \\
Duration of diabetes (years) & $13 \pm 8$ & $14 \pm 7$ \\
Systolic blood pressure (mmHg) & $115.0(110.0-120.0)$ & $120.0(112.5-122.0)$ \\
Diastolic blood pressure (mmHg) & $78.0(75.0-80.0)$ & $80.0(75.0-80.0)$ \\
BMI (kg/m²) & $27.5 \pm 0.2$ & $26.9 \pm 0.2$ \\
Fasting plasma glucose (mg/dL) & $165 \pm 33$ & $161 \pm 47$ \\
HbA ${ }_{1 \mathrm{c}}$ (\%) & $10.1 \pm 2.0$ & $9.6 \pm 1.9$ \\
Serum creatinine (mg/dL) & $0.90 \pm 0.08$ & $0.93 \pm 0.16$ \\
eGFR Modification of Diet in Renal & $81 \pm 13$ & $74 \pm 11$ \\
Disease (mL/min/1.73 m²) & & \\
ACR (mg/g creatinine) & $14.0(10.0-18.0)$ & $69.0(48.0-84.5)$ \\
Urinary NAG (Units/g creatinine) & $4.4(1.5-9.2)$ & $17.0(5.9-23.3)^{\mathrm{a}}$ \\
\hline
\end{tabular}

Data are presented as means \pm SD or median (range). BMI: body mass index. HbA : glycated hemoglobin. eGFR: estimated glomerular filtration rate. ACR: urinary albumin to creatinine ratio. NAG: N-acetyl-beta-D-glucosaminidase. Normoalbuminuria: ACR $<30 \mathrm{mg} / \mathrm{g}$ creatinine; Microabuminuria: $A C R=30-300 \mathrm{mg} / \mathrm{g}$ creatinine. $\mathrm{P}$ values of microalbuminuria $v s$. normoalbuminuria groups were calculated using the independent-samples $t$ test for normal distributed variables and the Mann-Whitney $U$ test for non-normal distributed variables. a $\mathrm{P}<0.001$ vs. normoalbuminuria.

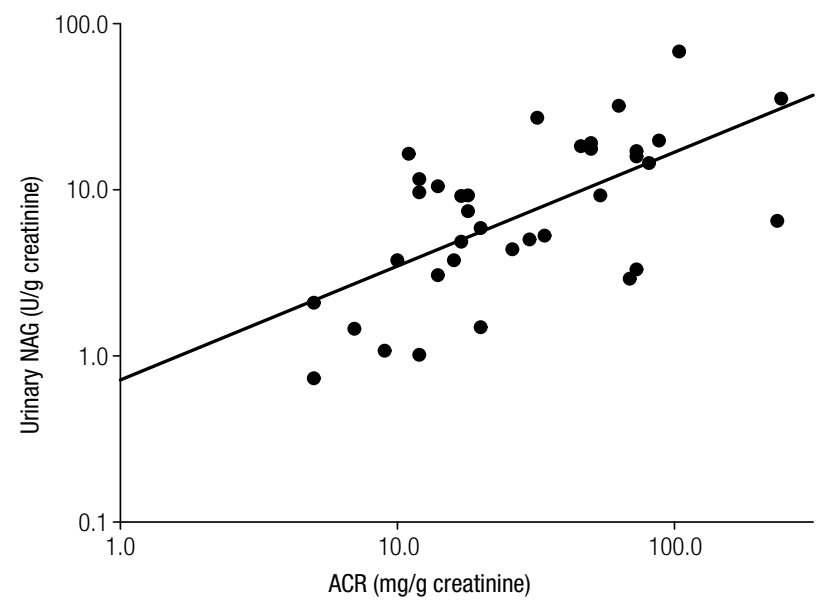

Figure 1. Correlation between urinary $\mathrm{N}$-acetyl-beta-D-glucosaminidase (NAG) and urinary albumin levels in type 2 diabetic patients $(n=36)$. Logarithm-transformed urinary NAG levels positively correlate with logarithm-transformed urinary albumin to creatinine ratio (ACR) levels ( $r=$ 0.628; $P<0.0001)$.

Table 2. Correlation (Pearson coefficients) of urinary NAG with age, blood pressure, BMI, glycemic control parameters, serum creatinine and eGFR in patients with type 2 diabetes mellitus

\begin{tabular}{lcc}
\hline \multirow{2}{*}{ Variable } & \multicolumn{2}{c}{ NAG } \\
\cline { 2 - 3 } & $\mathbf{r}$ & $\mathbf{P}$ \\
\hline Age & -0.259 & 0.160 \\
Systolic blood pressure & 0.134 & 0.436 \\
Diastolic blood pressure & 0.144 & 0.403 \\
BMl & -0.217 & 0.203 \\
Fasting glycemia & -0.201 & 0.239 \\
HbA $_{10}$ & -0.277 & 0.102 \\
Serum creatinine & -0.122 & 0.480 \\
eGFR & -0.0622 & 0.719 \\
\hline
\end{tabular}

BMl: body mass index. $\mathrm{HbA}_{1 \mathrm{C}}$ : glycated hemoglobin. eGFR: estimated glomerular filtration rate.

\section{DISCUSSION}

Although glomerular injury has classically been considered as the cause of early DN, studies in the last two decades have focused on the role of a concomitant or perhaps earlier occurrence of tubular injury in $\operatorname{DN}(2,3)$. In the present study we measured urinary NAG excretion, as a marker of tubular damage, in type 2 diabetic patients with normo- and microalbuminuria. We found that urinary NAG levels were significantly increased in patients with microalbuminuria compared to those with normoalbuminuria, thus corroborating previous studies performed in type 2 diabetic patients (8-10). We also observed a significant positive correlation between urinary NAG excretion and ACR which is consis- 
tent with the data reported by other studies in patients with T2DM (14) as well as in type 1 diabetic patients (15). These findings suggest that tubular dysfunction, evidenced by an increase in urinary NAG excretion, is already present in the microalbuminuria stage of $\mathrm{DN}$ in T2DM and that it becomes exacerbated with the degree of albuminuria. The association between the regression of microalbuminuria and the decrease in urinary NAG observed by Vaidya and cols. (16) in a prospective analysis performed in type 1 diabetic patients would support our hypothesis.

The lack of correlation between urinary NAG excretion and glycemic state are consistent with those results reported by other authors in type 2 diabetic patients $(9,14)$. However, data from the literature referred to T2DM are controversial $(10,17)$, while in type 1 diabetic patients such a relation is more clearly evidenced (15).

Despite the relatively small size of the sample and the cross sectional design of this study, we are able to state that urinary NAG levels are elevated in type 2 diabetic patients with microalbuminuria and that these levels correlate with ACR. These findings would suggest a possible clinical application of urinary NAG as a complementary marker for the detection of early renal disease in T2DM.

Acknowledgments: the authors would like to thank Professor Dr. Aldo Mottino for his critical review of the corrected manuscript and Dr. Cecilia Basiglio for language revision.

Financial support: this work was financially supported by the Universidad Nacional de Rosario (UNR), Argentina.

Disclosure: no potential conflict of interest relevant to this article was reported.

\section{REFERENCES}

1. American Diabetes Association. Standards of Medical Care in Diabetes-2013. Diabetes Care. 2013;36(Suppl 1):S11-66.

2. Gilbert RE, Cooper ME. The tubulointerstitium in progressive diabetic kidney disease: more than an aftermath of glomerular injury? Kidney Int. 1999;56:1627-37.
3. Comper WD, Hilliard LM, Nikolic-Paterson DJ, Russo LM. Disease-dependent mechanisms of albuminuria. Am J Physiol Renal Physiol. 2008;295:F1589-600.

4. Abbate M, Zoja C, Remuzzi G. How does proteinuria cause progressive renal damage? J Am Soc Nephrol. 2006;17:2974-84.

5. Hong CY, Chia KS. Markers of diabetic nephropathy. J Diabetes Complications. 1998;12:43-60.

6. Basturk T, Altuntas Y, Kurklu A, Avdin L, Eren N, Unsai A. Urinary $\mathrm{N}$-acetyl-B glucosaminidase as an earlier marker of diabetic nephropathy and influence of low-dose perindopril/indapamide combination. Ren Fail. 2006;28:125-8.

7. Ikenaga $H$, Suzuki $H$, Ishii $N$, Itoh $H$, Saruta T. Enzymuria in noninsulin-dependent diabetic patients: signs of tubular cell dysfunction. Clin Sci (Lond). 1993;84:469-75.

8. Nauta FL, Boertien WE, Bakker SJ, van Goor H, van Oeveren W, de Jong PE, et al. Glomerular and tubular damage markers are elevated in patients with diabetes. Diabetes Care. 2011;34: 975-81.

9. Piwowar A, Knapik-Kordecka M, Fus I, Warwas M. Urinary activities of cathepsin B, N-acetyl-beta-D-glucosaminidase, and albuminuria in patients with type 2 diabetes mellitus. Med Sci Monit. 2006;12:CR210-14.

10. Farvid MS, Djalali M, Siassi F, Farvid S. Association of glomerular and tubular dysfunction with glycaemic control, lipid, lipoprotein, apolipoprotein and antioxidant status in type 2 diabetes mellitus. Singapore Med J. 2007;48:840-6.

11. Fujita $H$, Morii T, Koshimura J, Ishikawa $M$, Kato $M$, Miura T, et al. Possible relationship between adiponectin and renal tubular injury in diabetic nephropathy. Endocr J. 2006;53:745-52.

12. Levey AS, Eckardt KU, Tsukamoto Y, Levin A, Coresh J, Rossert $J$, et al. Definition and classification of chronic kidney disease: a position statement from Kidney Disease: Improving Global Outcomes (KDIGO). Kidney Int. 2005;67:2089-100.

13. Murussi M, Murussi N, Campagnolo N, Pinho Silveiro S. Detecção precoce da nefropatia diabética. Arq Bras Endrocrinol Metab. 2008;52:442-51.

14. Udomah FP, Ekpenyong Ekrikpo U, Effa E, Salako B, Arije A, Kadiri S. Association between Urinary N-Acetyl-Beta-D-Glucosaminidase and Microalbuminuria in Diabetic Black Africans. Int $\mathrm{J}$ Nephrol. 2012;2012:235234.

15. Gibb D, Tomlinson P, Dalton N, Turner C, Shah V, Barratt T. Renal tubular proteinuria and microalbuminuria in diabetic patients. Arch Dis Child. 1989;64:129-34.

16. Vaidya $V$, Niewczas $M$, Ficociello $L$, Johnson A, Collings F, Warram $\mathrm{J}$, et al. Regression of microalbuminuria in type 1 diabetes is associated with lower levels of urinary tubular injury biomarkers, kidney injury molecule-1, and N-acetyl-b-D-glucosaminidase. Kidney Int. 2011;79:464-70.

17. Yamanouchi T, Kawasaki T, Yoshimura T, Inoue T, Koshibu E, Ogata $\mathrm{N}$, et al. Relationship between serum 1,5-anhydroglucitol and urinary excretion of $\mathrm{N}$-acetylglucosaminidase and albumin determined at onset of NIDDM with 3-year follow-up. Diabetes Care. 1998;21:619-24. 